\title{
Evidence-based Morning Report for Inpatient Pediatrics Rotations
}

Alan Schwartz, PhD, Jordan Hupert, MD, Arthur S. Elstein, PhD, and Peter Noronha, MD

\begin{tabular}{l}
\hline ABSTRACT \\
The authors describe a patient- \\
centered method for teaching evi- \\
dence-based medicine that is part \\
of the inpatient morning report for \\
pediatrics residents at the Univer- \\
sity of Illinois at Chicago. With li- \\
brary support, residents search for \\
evidence to answer their own ques- \\
tions about patients, and present it \\
at morning report \\
Acad. Med. 2000;75:1229.
\end{tabular}

The pediatrics residency at University of Illinois at Chicago College of Medicine includes month-long inpatient rotations for residents in their first and third years, and an eight-week rotation for medical students. A daily hour-long morning report teaching conference focused on case discussions is an important component of these rotations.

For the last 30 months, we have also instituted evidence-based morning report sessions once per week, with the goal of bringing the knowledge, skills, and attitudes required to practice evidence-based medicine $^{1}$ (EBM) to residents, clerks, and attending physicians in a way that directly relates to their patients and that minimally intrudes on the already busy residency schedule. The evidence-based sessions take place during the four or five Thursdays in each rotation. The ordinary morning report is compressed into 30 minutes, and the remaining 30 minutes are devoted to the EBM sessions. Faculty from the Department of Pediatrics, the Department of Medical Education, and the Library of Health Sciences participate. In addition, the head of the Department of Pediatrics and the inpatient medical director participate in these conferences, and their presence lends EBM sessions strong legitimacy.

The first week's session acquaints learners with the PICO (patient, intervention, comparison, outcome) method for formulating an answerable clinical question ${ }^{1}$ and introduces them to library staff. During each of the following weeks, a different resident-student team (of about four) is responsible for identifying a current patient case about which they have a question, formulating the question using PICO, meeting with the librarian to perform a literature search, and selecting an article that they believe best answers their question. They then present the details of their research process, a critical appraisal of the article, and a description of its application to the patient's case. Teams are aided in their interpretation of statistical results by two locally developed online calculators for diagnostic and therapeutic interventions. ${ }^{2}$ The discussion of article methods and results provides many "teachable moments" for concepts in research design and interpretation of statistical analyses.

Residents and students have reported that they enjoy the sessions, particularly because of their patient focus. Faculty have found them engaging and have commented that the clerks who participate ask more sophisticated questions during teaching rounds. Finally, one patient care issue was the focus of a session that eventually led to a change in ward policy for managing children with bronchiolitis.
A formal evaluation of the rotation's effect on participants' skills in applying evidence to clinical decision making is currently under way. Since one of the major skills of EBM is the ability to assess the quality of information, the evaluation concentrates on the degree to which residents alter their beliefs in the validity a clinical decision following exposure to strong versus weak evidence. Our initial findings suggest that after the rotation, residents are more likely to appropriately alter their beliefs when exposed to strong contrary evidence than they were before the rotation. ${ }^{3}$

Dr. Schwartz is assistant professor, Department of Medical Education, and adjunct assistant professor, Department of Pediatrics; Dr. Hupert is assistant professor, Department of Pediatrics; Dr. Elstein is professor, Department of Medical Education; and Dr. Noronha is clinical associate professor and director of the Division of Pediatric Education, Department of Pediatrics; all at the University of Illinois College of Medicine at Chicago.

Address correspondence and requests for reprints to Dr. Schwartz, Department of Medical Education (mc 591), University of Illinois at Chicago, 808 South Wood Street, 976 CME, Chicago, IL 60612-7309; e-mail: 〈alansz@uic.edu〉.

The authors acknowledge the support of Jerry Niederman, MD, Larry McLain, MD, and George Honig, $\mathrm{MD}$, in the evidence-based morning report efforts.

\section{REFERENCES}

1. Sackett DL, Richardson SR, Rosenberg W, Haynes RB. Evidence-Based Medicine: How to Practice and Teach EBM. London, U.K.: Churchill Livingstone, 1997.

2. Schwartz A. EBM and Decision Tools. 〈http:// araw.mede.uic.edu/ alansz/tools.html $\rangle$.

3. Schwartz A, Hupert J, Elstein AS. Evaluating physician's use of research evidence: a Bayesian approach [abstr]. Med Decis Making. 1999;19:524. 